\title{
Understanding Fundamentals of Safety to Develop Risk Informed Business Strategies for Disaster Risk Reduction
}

\author{
Mohammad Iqbal Zaffar Ansari \\ Deputy Chief Controller of Explosives, Petroleum and Explosives Safety Organisation (PESO), Guwahati, India \\ Email address: \\ mansari@explosives.gov.in \\ To cite this article: \\ Mohammad Iqbal Zaffar Ansari. Understanding Fundamentals of Safety to Develop Risk Informed Business Strategies for Disaster Risk \\ Reduction, Science Journal of Business and Management. Vol. 8, No. 4, 2020, pp. 154-160. doi: 10.11648/j.sjbm.20200804.11
}

Received: October 24, 2020; Accepted: November 9, 2020; Published: November 27, 2020

\begin{abstract}
Extreme changes are taking place in the climate and eco-system, thus we must act now to secure a safe, healthy and prosperous future of our planet earth. In fact there is no such thing as natural disaster we may term it as natural hazards, disasters often follow natural hazards. To understand the basic concepts and to adopt the sound practices of reducing the risk of disaster through systematic efforts by analysing and reducing the causal factors responsible for causing disasters is need of the hour for scientific community, law enforcement agencies and law abiding citizens of the country. Thus we have to think wisely and act smartly on all of our actions in every sphere of our works to save the mankind from future inferno of disasters. Through this research paper an effort has been made to put light on the need of developing resilience society for explosion mitigation amongst all the commercial explosives stake holders of India in line with the United Nation's Sendai Framework Regulations for Disaster Risk Reduction. The statutory authority for controlling the current state of affairs in India is Petroleum and Explosives Safety Organization, which was formerly known as department of explosives and is entrusted with the administration of Explosives Act1884 and in service of the nation since 1898 with its Safety First Motto. Its last twelve year's data of reported explosion accidents occurred in India are scientifically analyzed to draw the conclusions and recommendations were offered based on the inferred results with directions for future research, which is to be further explored in light of the available primary data by developing high end explosion scenarios to save the lives of high explosives stake holders from the future inferno of explosion accidents happening frequently in India, in spite of having quite intensive inspections mechanism and taking all due care and adopting all effective and preventive measures to avoid any explosion accident during the process of manufacturing, storage, transport, handling, possession for sale or use of commercial high explosives and manufactured fireworks in India. Confidently it is expected that the suggested recommendations will prove to be a mile stone in establishing the explosion resilient society for explosion mitigation and reducing the risk of disaster amongst commercial explosives stake holders of India and will inflame statutory authorities and law enforcing agencies to act wisely in the interest of people safety to avert apocalyptic situation like Beirut.
\end{abstract}

Keywords: Commercial Explosives, Controller of Explosives, Disaster Risk Reduction, Explosion Mitigation, Explosion Resilience, Manufactured Fireworks, People Safety, Sendai Framework

\section{Introduction}

There are many sectors outside of oil and gas industries such as mining, chemicals, maritime, transport and aviations where the use of risk evaluation method for analyzing and managing risk is rapidly growing, though its use in the commercial High Explosives Manufacturing Units (HEMU) and Fire Works Industries (FWI) is not so wide spread in the Indian context. It is therefore envisaged that the Petroleum and Explosives Safety Organisation (PESO), must pay emphasis and encourage user industries under their jurisdiction to evaluate involved risk before start of any business or commercial explosives manufacturing activities to analyze and demonstrate the existence of any casual relationship involved in high risk scenarios and to know whether the designed level of control can sustain the major hazard scenarios and are the way to make a decisions about current level of controls are sufficient enough to keep the anticipated risk, at as low as reasonably practicable (ALARP) level. Since the Risk is not subjective in nature and Hazard is something that if a loss of control of 
hazard happens, an abnormal and dangerous situation may arise. The event that leads to loss of existing control to overcome the hazard is termed as Top Event and by virtue of this top event the industry is now fully exposed to the potential harm which may lead to unforeseen situations resulting in fire and explosion accidents. If the safety management system is in place in the industry, it can tackle the situations from going out of control and adopt necessary safety measures to prevent risk in the highly sensitive areas of explosives manufacturing and handling. Therefore it is very important to understand fundamentals of safety to develop risk-informed business strategies for disaster risk reduction aiming to simplify the effectiveness of manufacturing operations and explosives handling processes to reduce the number of accidents and to promote co-operation and coherence to find a way to achieve the goal of ZERO accident together for all the stake holders of the commercial explosives industry in India. Thus it is now envisaged that Indian commercial High Explosives Manufacturing Units and the Fire Work Industries must now leapfrog to the expectations of their global counterparts to drive uniformity and save the man kind in line with United Nation's Sendai Framework [1] guidelines for Disaster Risk Reduction (DRR) [2] and prepare themselves for Explosion Mitigation (EM) and to develop Explosion Resilience Societies (ERS) amongst all the Indian explosives industry's stake holders as early as possible or by the beginning of next decade under the egis of PESO and esteemed and able guidance of its Controller of Explosives (CEs) as defined under the Explosives Rules 2008 [3] revised, amended 2019, and framed under the Explosives Act 1884 [4] to comply the UNDRR's Sendai framework resolutions adopted at Japan. The basic objectives of this research paper is to create awareness, provide expertise, share knowledge, to develop risk-informed business strategies and implement innovative and collaborative activities to achieve the targets of Zero Accidents amongst the commercial explosives stake holders of India so as to ensure that engaged peoples are not exposed to risk in their day-to-day working life per the UNDRR Sendai Framework and ARISE five commitments.

\section{Theoretical Background}

The theory behind explosions involving commercial explosives in India has to be first understood in a quite scientific manner, by analyzing its primary root causes, extent of damages made in terms of loss of lives and property and in context of demography of its origin. Scientifically it is a proven fact as described in an ancient Latin manuscript that primary causes of most of the explosion accidents are Friction, Impact, Electrical Spark and Heat only and in short we may term it as FISH [5]. Thus one has to take all possible preventive steps and develop resilience among its users and educate them in proper manner to counter these factors responsible for causing explosion accidents by using latest DRR techniques [6] to reduce future inferno in case of fire and how to mitigate in case of explosion accidents for preventing more loss of lives and properties. PESO has played a vital role in compiling the data of explosion accidents of Indian origin which has to be analyzed further in a quite scientific manner for explosion mitigation and disaster risk reduction for safety of all its stake holders engaged in commercial explosives business in India by upholding the flag of Safety First Motto.

\subsection{Literature Survey}

It is reported that in past three decades the frequency of disasters has almost doubled and the financial losses have tripled. If no investment is made in DRR and building resilience the sustainable developmental goal will never be achieved. Disaster affects all people and all sectors, it never discriminate as nothing undermines development and prosperity like a disaster. Thus we must ensure building of resilient societies [7]. The DRR techniques reduces the damages caused by the natural hazards like earthquakes, floods, droughts and cyclones, through an act of identifying the risk and reducing the same for prevention of hazard. It also reduces exposure to hazards, lessening vulnerability of people and property. Thus management of land and the environment, and efforts for improving the preparedness and methods of early detection and advance warning systems for adverse events may perhaps be adopted for reducing economic losses [8]. Scientifically now it is a proven fact, that disasters are not natural at all. Thus one has to understand the disaster risk in terms of its mathematical model "(1)". The disaster risk (R) is defined as equal to vulnerability (V) of exposure multiplied by the impact of hazard $(\mathrm{H})$ and divided by the capacity $(\mathrm{C})$ of coping [9]. Hazard itself do not constitute disaster, but the magnitude of disaster is described as adverse effects which hazards have on lives, property, infrastructure and environmental damage and cost of post disaster recovery and rehabilitations.

$$
(\mathrm{R})=(\mathrm{V}) \times(\mathrm{H}) /(\mathrm{C})
$$

Severity of a disaster is dependent on how much impact a hazard has on the society, ecology and environment of a particular geographic area comprising different demography of people. The scale of the impact of a disaster and its severity in turn is found to be dependents on the choices people makes in their surrounding environment for ease of their lives. These choices relates to how people cultivate their foods, how and where they build their homes, what type of administration they have, how their economy works and even what they teach to their children. Each of their action and decisions makes them vulnerable to the disasters or more resilient to their society [10]. As per recent report published, the human race has never before faced such large and complex threats of disasters as prevailing now. Latest DRR technique aims to prevent new threats and reduces existing risk of disaster, strengthening the resilience of people, systems and approaches. DRR sits at the heart of the world's most pressing concerns: climate change, displacement, urbanization, pandemics, protracted crises and collapse of emerging economies [11].

\subsection{Sendai Framework}

The UNDRR's Sendai Framework, [12] aims to achieve the 
substantial reduction of disaster risk and losses in lives, livelihoods and health and in the economic, physical, social, cultural and environmental assets of persons, businesses, communities and countries, by the year 2030. Special representative of the secretary general for UN disaster risk reduction, Mami Mizutori [13], has set seven global targets and four priorities for taking immediate action to counter the same [14].

\subsubsection{Seven Global Targets}

Target1. Substantially reduce global disaster mortality by 2030 , aiming to lower average per 100,000 global mortality rates in the decade 2020-2030 compared to the period 2005-2015. Target2. Substantial4y reduce the number of affected people globally by 2030 , aiming to lower average global figure per 100,000 in the decade 2020 -2030 compared to the period 2005-2015. Target3. Reduce direct disaster economic loss in relation to global gross domestic product (GDP) by 2030. Target4. Substantially reduce disaster damage to critical infrastructure and disruption of basic services, among them health and educational facilities, including through developing their resilience by 2030. Target5. Substantially increase the number of countries with national and local disaster risk reduction strategies by 2020 . Target6. Substantially enhance international cooperation to developing countries through adequate and sustainable support to complement their national actions for implementation of this Framework by 2030. Target7. Substantially increase the availability of and access to multi-hazard early warning systems and disaster risk information and assessments to the people by 2030 [15].

\subsubsection{Four Action Priorities}

Priority1. Understanding disaster risk- Disaster risk management should be based on an understanding of disaster risk in all its dimensions of vulnerability, capacity, exposure of persons and assets, hazard characteristics and the environment. Such knowledge can be used for risk assessment, prevention, mitigation, preparedness and response. Priority2. Strengthening disaster risk governance to manage disaster risk-Disaster risk governance at the national, regional and global levels is very important for prevention, mitigation, preparedness, response, recovery, and rehabilitation. It fosters collaboration and partnership. Priority3. Investing in disaster risk reduction for resilience- Public and private investment in disaster risk prevention and reduction through structural and non-structural measures are essential to enhance the economic, social, health and cultural resilience of persons, communities, countries and their assets, as well as the environment. Priority4. Enhancing disaster preparedness for effective response and to "Build Back Better" in recovery, rehabilitation and reconstruction- The growth of disaster risk means there is a need to strengthen disaster preparedness for response, take action in anticipation of events, and ensure capacities are in place for effective response and recovery at all levels. The recovery, rehabilitation and reconstruction phase is a critical opportunity to build back better, including through integrating disaster risk reduction into development measures [16].

\subsubsection{Five Commitments}

UNDRR is working with the private sector to risk-proof value chains, advocate with governments for necessary support, develop risk-informed infrastructure, and ensure that staff and partners are not exposed to risk in their day-to-day working lives. We too have to be in this together to full fill these five commitments of ARISE as advocated by UNISDR [17]. Commitment1. Raise Awareness: Awareness raising with respect to disaster risk and mobilization of the private sector. Commitment2. Influence: Exercising influence in respective spheres of expertise. Commitment3. Share Knowledge: Share knowledge, experience and good practices amongst the private sector. Commitment4. Catalyze: Be a catalyst to generate innovation and collaboration in developing risk-informed business strategies. Commitment5. Implement: Implement projects and activities to achieve the targets of the UNDRR's Sendai framework resolutions.

\section{Indian Scenario}

India has a very disastrous history of commercial explosives explosions. Every year lots of lives and properties were being lost due to not taking lessons from the past happenings and by not analyzing the root cause of the primary reasons in a scientific manner i.e. Friction, Impact, Spark and Heat, which were found responsible for fire and explosion accidents. Let us have a disastrous look on the available primary data of reported and investigated fire and explosion accidents in India involving commercial explosives occurred during last 12 years through Fish Bone Analysis the extended form of classical Bow Tie Analysis [18] used for identifying the safety risk priorities and analyzing the risk model to find out the root cause of these reoccurring accidents using an advance safety management system in a scientific manner.

\section{Data Analysis}

While categorizing the accident investigation data of the fire and explosion accidents occurred during last twelve years involving commercial explosives in India, amazing facts are found to be emerging which needs immediate attention of the safety regulators to formulate stringent safety regulations to control the future fire and explosion accidents and loss of human lives, materials, machines and precious money of the stake holders engaged in commercial explosives business in India. Let us have a distress look and act as per Simon de Beauvoir advises to change your life today, don't gamble on the future, act now without delay. 
Table 1. Retrieved from chapter 12 of PESO annual reports

\begin{tabular}{lllll}
\hline SrNo. & $\begin{array}{l}\text { Reporting Years }\left(\mathbf{1}^{\text {st. }^{*}} \text { April to 31 }\right. \\
\text { March) }\end{array}$ & $\begin{array}{l}\text { No. of Accidents Cases Investigated By } \\
\text { PESO. }\end{array}$ & $\begin{array}{l}\text { Total Nos. of Persons } \\
\text { Killed. }\end{array}$ & $\begin{array}{l}\text { Total Nos. of Persons } \\
\text { Injured. }\end{array}$ \\
\hline 01 & $2008-2009$ & 11 & 61 & 60 \\
02 & $2009-2010$ & 18 & 85 & 121 \\
03 & $2010-2011$ & 20 & 48 & 37 \\
04 & $2011-2012$ & 28 & 58 & 56 \\
05 & $2012-2013$ & 25 & 46 & 43 \\
06 & $2013-2014$ & 22 & 73 & 57 \\
07 & $2014-2015$ & 21 & 90 & 113 \\
08 & $2015-2016$ & 25 & 130 & 515 \\
09 & $2016-2017$ & 32 & 171 & 68 \\
10 & $2017-2018$ & 30 & 94 & 41 \\
11 & $2018-2019$ & 26 & 61 & 64 \\
12 & $2019-2020$ & 33 & 43 & \\
\hline
\end{tabular}

\section{Conclusions}

Since the previous reported accident investigation data involving fire and explosion accidents occurred due to commercial explosives in India were not readily available on line on the peso website. Thus an attempt has been made by the author to retrieve the same from individual Annual Reports of the organization of last 12 years for throwing lights to highlight the hidden facts regarding the emerging trends of its occurrence across India amongst the stake holder's premises used for commercial explosives business [19]. Each and every investigated accident involving fire and explosion accidents were individually analyzed using excel spread sheets and segregated for commercial explosives premises including fireworks premises. Only those reported accident cases were selected which were found governed by the Explosives Rules-2008 utilizing excel worksheet pivot tables.

1. Every year on an average 24 Nos. of Accidents involving commercial explosives explosion accidents happens in India. 2. Every year on an average 80 Nos. of persons gets Killed involving commercial explosives explosion accidents happens in India. 3. Every year on an average 106 Nos. of persons gets injured involving commercial explosives explosion accidents happens in India. 4. Every year on an average 27 Nos. of persons gets Killed due to Friction of commercial explosives/ or in its ingredient composition resulting in explosion accidents in India. 5. Every year on an average 19 Nos. of persons gets Killed due to Ignition of commercial explosives/ or in its ingredient composition resulting in explosion accidents in India. 6. Every year on an average 20 Nos. of persons gets Killed due to Spark generation of commercial explosives/ or in its ingredient composition resulting in explosion accidents in India. 7. Every year on an average 14 Nos. of persons gets Killed due to Heat generation in commercial explosives/ or in its ingredient composition resulting in explosion accidents India. 8. Every year on an average 32 Nos. of persons gets Injured due to Friction of commercial explosives/ or in its ingredient composition resulting in explosion accidents in India. 9. Every year on an average 51 Nos. of persons gets Injured due to Ignition of commercial explosives/ or in its ingredient composition resulting in explosion accidents in India. 10. Every year on an average 15 Nos. of persons gets Injured due to Spark generation of commercial explosives or in its ingredient composition resulting in explosion accidents in India. 11. Every year on an average 08 Nos. of persons gets Injured due to Heat generation in commercial explosives/ or in its ingredient composition resulting in explosion accidents India. 12. Every year on an average the ratio of Nos. of persons gets Killed with respect to Nos. of persons gets injured involving commercial explosives explosion accidents happens in India is found to be approx 1: 1.325. 13. Every year on an average the ratio of Nos. of persons gets Injured with respect to Nos. of persons gets Killed involving commercial explosives explosion accidents happens in India is found to be approx 1: 0.755 .14 . Every year on an average the percentage of persons gets Killed with respect to the percentage of persons gets injured involving commercial explosives explosion accidents happens in India is found to be approx 43\%. 15. Every year on an average the percentage of persons gets Injured with respect to the percentage of persons gets Killed involving commercial explosives explosion accidents happens in India is found to be approx 57\%. 16. The last but not the least in a nut shell it can be finally inferred on the basis of last 12 years accidents data that 02 Nos. of Accidents involving commercial explosives explosion accidents are happening per month in India, with an average Killing of at least 07 persons and Injuries to at least 09 persons on a monthly basis. Considering the significance of its outcomes, it is recommended to develop risk informed business strategies for disaster risk reduction in this domain for coming decade as per UNDRR's framework 2020-2030.

\section{Limitations}

The available data also includes manufactured fireworks related accidents which were found to be most common in the southern part of India particularly in the Sivakasi Town situated in the Virdhu Nagar District near the temple city of Madurai in the state of Tamil Nadu and adjacent districts of Kerala State. It was prominently noticed that out of four factors responsible for fire and explosion accidents in the manufactured fireworks type of commercial explosives, the most common cause was found to be Friction. Which include use of Iron Implement, Scratching, Cutting, Drying and other unsafe acts causing friction to sensitive white powder 
chemical compositions, its purity, excess storages, and exceeding man power limits and use of non compatible and non permitted chemicals. Impact generally includes fall of heavy objects, use of stone or iron implements, handling chlorate mixtures, and other negligence works like fuse cutting, unsafe crimping and detonation. Spark may be attributed broadly to generation of all types of electrical spark, short circuiting, arcing, lightning, electro static charge generation, use of inverter, battery, loose electrical wiring and non flame proof electrical equipments and handling non compatible explosives or its ingredients etc. Whereas the Heat is generated mainly due chemical reactions as a result of decomposition of chemicals and use of non compatible ingredients, physical reactions due to, friction, Impact, and generation of heat due to lighting fire, rise in pressure, excess temperature, waste burning, hot drying, overheating, and presence of other source of external fire, excess storage of finished as well as ingredient chemicals and mostly by the unsafe acts of workers involving smoking, cooking or switching lights on at site.

\section{Recommendations}

PESO will be completing 125 glorious years of its foundation in the year 2023 by operating in the country under various ministries of the Govt. of India since its inception from $9^{\text {th }}$ of Sept. 1898, with safety first motto and was formerly known as Department of Explosives (Do Ex). PESO's ultimate goal is zero accidents because it believes that all accidents are preventable. Only one has to conduct his business in a responsible manner and adhere to the internationally accepted safe practices as envisaged by UNDRR's Sendai Framework [20]. Since safety performance is everyone's responsibility and every one each have a duty to intervene to prevent unsafe actions and to reinforce good behavior through demonstrating excellent safety leadership to create outstanding safety culture around them for protection of the health and safety of all the stake holders, who so ever are affected by their services, their physical assets, their reputations and the environment surrounding their premises [21]. As safety in all their operations is a very critical success factor for development of their business [22]. In implementing this type of safety policy PESO shall have to ensure that, it will serve as Mentor to provide complete directions, full fledge education, Behavior Based Safety (BBS) [23] Training and enforce strict supervision to ensure that all its stake holders become self competent and educated enough to know their own accountabilities, learn to change their required behavior and understand the consequences of non-compliance of the recommendations made by their regulators in the interest of ensuring safety of their people, their property and pride (3P) of their nation as a whole [24].

The PESO, Controllers as defined under Explosives Act 1884, and Explosives Rules 2008, must therefore clearly understand the factors responsible for fire and explosion accidents and try to fix them during the course of their comprehensive inspection of the premises even though they are not approved or licensed by them. They must not leave any stone un turn to enforce all relevant safety standards and must not leave enforcement of even smallest things required for ensuring safety, any possibilities of omissions of even a tiny looking requirement for which even they have to convince the occupier of the premises by elaborating its importance in terms of its role in prevention of fire and explosion accidents shall not be left for complying at a later stage. For example to counter Friction all implements be checked thoroughly that it shall not be made of iron or stone and purity of ingredients be checked that it is grit free and as per the required standards in terms of its quality and quantity. To prevent Impact proper handling and care must be taken to avoid fall of any heavy objects on the highly sensitive chemical compositions being handled at site, its proper handling during manufacturing process and storage and its dispatch. Generation of Spark can be reduced by use of flame proof electrical equipments, conduced electrical wirings and proper bonding and lightening arrestors and avoiding friction by utilizing proper machinery, tools and non sparking implements. While Heat must be restricted by controlling rise in temperature, pressure and other source of ignitions, controlling external fire and unsafe burning of waste, cooking and of course smoking etc. India's most beloved ex-president Late A P J Abdul Kalam used to say: when learning is purposeful, creativity blossoms, when creativity blossoms, thinking emanates, when thinking emanates, knowledge is fully lit, when knowledge is lit, economy flourishes.

The past safety theories were not able to define the risk in its real sense, though they were warning enough against the unnoticed events which were not properly exposed. However the modern safety management system enable controllers to foresee the dangerous situation in advance and direct them to adopt adequate safety measures in anticipation through disciplined and scientific detection in early stages, near miss reporting, incident recording and assessing the scenarios that have already been taken place in the past. As there exist a very thin line between near misses and unsafe acts and the dangerous situations may not be much clear. Thus they have to count on the early detection system which can only be made possible from the committed professionals that have been adequately trained and duly motivated too to handle and analyze the sequence of events that may lead from the mere presence of any explosives substance at a given place to a final non intentional explosion comprised due to existence of any available source of ignition. Fire may generate due to friction, ignition spark or heat as a result of chemical reaction, decomposition or spurious ingredient mixtures, that is able to cause fire and explosion accident and may propagate further and leads to sympathetic detonation or induced explosion at a later stage leading to devastating catastrophic situation running out of proportions causing severe injuries and fatalities at site and surroundings. Therefore in light of the above eye opening findings, it is highly recommended in the interest of safety that capacities of PESO controllers may be build further for preparing future explosion mitigation plans and developing explosion resilience society amongst all the high explosives stake holders of India to save them future 
inferno of disasters caused due to incremental rise in the frequency of fire and explosion accidents occurring in India.

\section{Future Directions}

George Herbert says: Do not wait; the time will never be just right. Start where you stand and work with whatever tools you may have at your command, and better tool will be found as you go along. All the controllers must therefore ensure that existing conditions do not allow the sequence of events to happen within their assigned jurisdictions and devote their career to prevent the involved risk in all the field of high explosives manufacturing, handling, storage, sale, use, transport, import and export at all time. The smallest deed is better than the greatest intention: John Burroughs, Therefore all the PESO Controllers has to arise up to the expectations of their esteem stake holders for Disaster Risk Reduction, and prepare them for explosion mitigation by adapting latest DRR techniques in every stream of their working for safe future and explosion free premises by making explosion resilient society amongst all the stake holders so that they can develop risk-informed business strategies for operating commercial explosives business safely in India.

Hope generation next researchers will learn lesson from the recent apocalyptic situations created due to Beirut Incident of 4 Aug 2020, leaving 135 persons dead and more than 300,000 injured, primarily due to unauthorized storage of 2750 Tons of Ammonium Nitrate consignment kept unattended at centrally located dock yard's ware house of port city of Lebanon. This devastating explosion accident is truly an eye opener as it also occurred due to the hellhole of commercial explosives explosion which impacted the country's economy very badly. Thus it is thought to ignite the minds of young scientists working on this domain through this case based research paper on illustrated Indian scenario to raise their aspirations, to enable them to brain storm, to think rigorously on the issues raised, to work hard and to develop risk informed business strategies for disaster risk reduction so as to drastically reduce the heavy economic losses incurring worldwide up to the tune of 2.97 Trillion US\$, claiming 1.23 Million lives and affected 4 Billion people, many on more than one occasion as reported by the UNDRR's Emergency Events Database of Center for Research on the Epidemiology of Disasters, in recently released report titled "Human Cost of Disasters: An overview of the last 20 years (2000-2019)".

\section{Acknowledgements}

The author is thankful to UNDRR for courtesies extended with invite to attend AGM as member ARISE-INDIA and for providing full literature support for this research paper, the views expressed in this article do not necessarily reflect the views of the PESO, DPIIT or the Govt. of India, in particular. Author has not received any sponsorship for this publication and there exist no conflict of interest.

\section{References}

[1] Lucy Pearson and Mark Pelling. (2015). Negotiation process and prospects for science and practice: The UN Sendai Framework for Disaster Risk Reduction 2015-2030. World Scientific Publishing Company, King's College London, UK. Global Network of Civil Society Organizations for Disaster Reduction, UK, J Extreme Events, Vol. 2, No 1 (2015) 1571001

[2] Dewald van Niekerk. (2011). Introduction to disaster risk reduction. African Center for Disaster Studies, USAID, OFDA, NWU, Potchefstroom Campus South Africa, Document Version: ASCD1.

[3] Explosives Rules. (2008). Last Accessed on 09/11/2020, At http://dgms.gov.in/writereaddata/UploadFile/ExplosivesRules, \%202008.pdf

[4] Explosives Act. (1884). Last Accessed on 09/11/2020, At https:/dipp.gov.in/sites/default/files/Explosive_Act_1884_0.pdf

[5] Tony, Rowe. (2014). Tony's tale-piece: AEL Mining Services. SAFEX Newsletter, CH - 1807 BLONAY, Switzerland, No.51, 4th Qtr, 2014, page 29-34

[6] Rose, Christel; Debling, Florentina; Safaie, Sahar; Houdijk, Ruud. (2019). Words into action guidelines: developing national disaster risk reduction strategies. United Nations Office for Disaster Risk Reduction, Accessed at https://www.undrr.org/publication/words-action-guidelines-de veloping-national-disaster-risk-reduction-strategies

[7] E. Garnier. (2019). Disaster prevention and management: lessons learned from the past for a better resilience to contemporary risks. French National Centre for Scientific Research, CNRS, Chrono-Environmental Laboratory, University of Besancon, Paris France; Retrieved at emerald insight on 24 Sept 2019, in press

[8] Myung Hee, Kim. (2020). Implementation system and strategic implications for disaster risk reduction by the United Nations. Journal of the Korea Convergence Society, Shahmyook University, Korea, Vol. 11. No. 1, pp. 211-219, ISSN 2233-4890 / eISSN 2713-6353

[9] Dewald van Niekerk. (2011). Defining the concepts: Introduction to disaster risk reduction. United State Agency for International Development. South Africa Training Programme, Chapter 2, Page 15, UNISDR: 2002: $41 \&$ 47, Accessed at https://www.preventionweb.net/files/26081_kp1 concepdisaste rrisk1.pdf

[10] Ilan, Kelman. (2020). Introduction to five years of the Sendai framework for disaster risk reduction. International Journal of Disaster Risk Science, University College, London, WC1E, 6BT, UK, Vol. 11

[11] GAR. (2019). Global assessment report on disaster risk reduction for 2019. United Nations Office for Disaster Risk Reduction, p1-425, ISBN/ISSN/DOI, 978-92-1-004180-5, Accessed at https://www.undrr.org/publication/global-assessment-report-di saster-risk-reduction-2019

[12] UN, HQ. (2015). Sendai framework for disaster risk reduction: 2015-2030. United Nation Office for Disaster Risk Reduction, adopted at third UN World Conference on Disaster Risk Reduction (WCDRR) in Sendai, Japan, p1-32, Accessed at https://www.undrr.org/publication/sendai-framework-disasterrisk-reduction-2015-2030 
[13] Mami, Mizutori. (2018). Economic losses and displacement should drive disaster risk reduction efforts. UN Chronicle, Asian Ministerial Conference on DRR; Opening remarks by The Special Representative of the United Nation Secretary General, For Disaster Risk Reduction, Ulaanbaatar, Mongolia

[14] UNDRR. (2020). Monitoring the implementation of Sendai framework for disaster risk reduction 2015-2030: A snapshot of reporting for 2018. Sendai Framework Snapshot Report for 2018 , UNDRR, Europe Accessed at

https://www.undrr.org/publication/monitoring-implementation-s endai-framework-disaster-risk-reduction-2015-2030-snapshot

[15] UNISDR. (2016). The Sendai, 7 Campaign, 7 Targets, 7 Years: (2016-2022). UNDRR, Accessed at https://www.preventionweb.net/files/54917_iddr2017conceptn ote.pdf

[16] UN. HQ. (2015). The four priorities: for action to prevent new and reduce existing disaster risks; under Sendai framework for disaster risk reduction: (2015-2030). Adopted by UNDRR, Accessed at https://www.preventionweb.net/publications/view/43291

[17] UNDRR. (2020). The five commitments of ARISE: Private sector alliance for disaster resilient societies. Led by Ms Irina Zodrow, Programme officer of the Partnerships Unit, Accessed at https://www.preventionweb.net/arise/participate/

[18] CAA. (2015). How to develop a bowtie risk model: Implementing bowtie into safety management for identifying safety risk priorities. Civil Aviation Authority Publications, UK, Accessed at https://www.caa.co.uk/Safety-initiatives-and-resources/Worki ng-with-industry/Bowtie/Implementing-into-safety-manageme $\mathrm{nt} /$ Implementing-bowtie-into-safety-management-systems/

[19] PESO, Annual Reports. (2008-2019). Last Accessed on 09/11/2020. At https://peso.gov.in/AR1.aspx

[20] Amina. Aitsi-Selmi, Kevin Blanchard \& Virginia Murray. (2016). Ensuring science is useful, usable and used in global disaster risk reduction and sustainable development: a view through the Sendai framework lens. Palgrave Communications, vol. 2, Article number: 16016

[21] Malgorzata, Jasiulewicz-Kaczmarek, Katarzyna, Szwedzka, Marek, Szczuka. (2015). Behavior based intervention for occupational safety-Case Study. Poznan University of Technology, Poland, Procedia Manufacturing 3, 4876-4883

[22] S. Tuncel, H. Lotlikar, S. Salem, N. Daraiseh. (2006). Effectiveness of behavior based safety interventions to reduce accidents and injuries in workplaces: critical appraisal and meta-analysis. The NCBI. Center for Reviews and Dissemination, University of York., Bookshelf ID: NBK72330, Accession Number: 12007007033 Accessed at https://www.ncbi.nlm.nih.gov/books/NBK72330/

[23] Rosliza Osman, Noorhasimah Awang, Syed Abdul Hamid, Syed Hassan, Norsyahidah Mohammad Yusof. (2015). Level of awareness on behavior based safety (BBS) in manufacturing industry towards reducing workplace incidents. International Journal of Education and Research, Vol. 3, No. 1, January 2015

[24] Katie Peters, Emma Lovell. (2020). Reducing the risk of protracted and multiple disaster displacements in Asia-Pacific. United Nations Office for Disaster Risk Reduction - Regional Office for Asia and Pacific, Overseas Development Institute, Oceania. Accessed at https://www.undrr.org/publication/reducing-risk-protracted-an d-multiple-disaster-displacements-asia-pacific

\section{Biography}

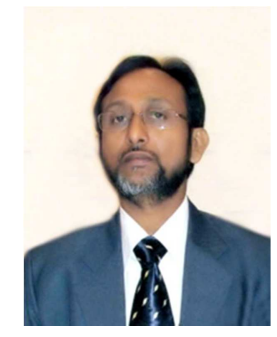

Mohammad Iqbal Zaffar Ansari is an Alumni of AMU, and an Accredited Management Teacher. He works at Petroleum and Explosives Safety Organisation, Guwahati, Assam, India. He has published several articles in academic journals in Arabian Journal of Business and Management Review (Kuwait Chapter), International Journal of Research and Scientific Innovation Society Australia, International Journal of Research in Business Studies and AIMA Journal of Management and Research, New Delhi. His area of interest includes Behavioural Safety Training, Climate Changes, Clean Fuels, Disaster Risk Reduction, Entrepreneurships, Green Technologies, Human Resource Management, Innovations, Resilience Development, Strategic Capacity Building Training and Up Skilling. 